\title{
Quantitative mass spectrometry of TATA binding protein-containing complexes and subunit phosphorylations during the cell cycle
} \author{
WWM Pim Pijnappel ${ }^{\dagger 1}$, Annemieke Kolkman ${ }^{\dagger 2}$, Marijke PA Baltissen ${ }^{1}$,
} Albert JR Heck² and HT Marc Timmers*1

\begin{abstract}
Address: ${ }^{1}$ Netherlands Proteomics Centre, Department of Physiological Chemistry, University Medical Center Utrecht, Universiteitsweg 100,3584 CG Utrecht, the Netherlands and ${ }^{2}$ Netherlands Proteomics Centre, Biomolecular Mass Spectrometry and Proteomics Group, Bijvoet Center for Biomolecular Research and Utrecht Institute for Pharmaceutical Sciences, Utrecht University, Faculty of Science, Padualaan 8, 3584 CH Utrecht, the Netherlands

Email: WWM Pim Pijnappel - W.W.M.Pijnappel@umcutrecht.nl; Annemieke Kolkman - A.Kolkman@umcutrecht.nl;

Marijke PA Baltissen - M.P.A.Baltissen@umcutrecht.nl; Albert JR Heck - A.J.R.Heck@uu.nl; HT Marc Timmers* - H.T.M.Timmers@umcutrecht.nl

* Corresponding author †Equal contributors
\end{abstract}

Published: 24 December 2009

Proteome Science 2009, 7:46 doi:10.1186/1477-5956-7-46

This article is available from: http://www.proteomesci.com/content/7///46

(c) 2009 Pijnappel et al; licensee BioMed Central Ltd.

This is an Open Access article distributed under the terms of the Creative Commons Attribution License (http://creativecommons.org/licenses/by/2.0), which permits unrestricted use, distribution, and reproduction in any medium, provided the original work is properly cited.
Received: 10 July 2009
Accepted: 24 December 2009

\begin{abstract}
Background: Progression through the cell cycle is accompanied by tightly controlled regulation of transcription. On one hand, a subset of genes is expressed in a cell cycle-dependent manner. On the other hand, a general inhibition of transcription occurs during mitosis.

Genetic and genome-wide studies suggest cell cycle regulation at the level of transcription initiation by protein complexes containing the common DNA-binding subunit TATA binding protein (TBP). TBP is a key player in regulating transcription by all three nuclear RNA polymerases. It forms at least four distinct protein complexes with TBP-associated factors (TAFs): SLI, B-TFIID, TFIID, and TFIIIB. Some TAFs are known to remain associated with TBP during the cell cycle. Here we analyze all TAFs and their phosphorylation status during the cell cycle using a quantitative mass spectrometry approach.

Results: TBP protein complexes present in human cells at the G2/M and GI/S transitions were analyzed by combining affinity purification with quantitative mass spectrometry using stable isotope labeling with amino acids in cell culture (SILAC). Phosphorylations were mapped and quantified after enrichment of tryptic peptides by titanium dioxide. This revealed that subunit stoichiometries of TBP complexes remained intact, but their relative abundances in nuclear extracts changed during the cell cycle. Several novel phosphorylations were detected on subunits of the TBP complexes TFIID and SLI. G2/M-specific phosphorylations were detected on TAFI, TAF4, TAF7, and TAFI4I/TAFID, and GI/S-specific dephosphorylations were detected on TAF3. Many phosphorylated residues were evolutionary conserved from human to zebrafish and/or drosophila, and were present in conserved regions suggesting important regulatory functions.
\end{abstract}

Conclusions: This study provides the first quantitative proteomic analysis of human TBP containing protein complexes at the G2/M and GI/S transitions, and identifies new cell cycle-dependent phosphorylations on TAFs present in their protein complex. We speculate that phosphorylation of complex-specific subunits may be involved in regulating the activities of TBP protein complexes during the cell cycle. 


\section{Background}

Gene transcription is regulated during the cell cycle. During mitosis, transcription by all three nuclear RNA polymerases (pols) is inhibited $[1,2]$. In addition, 5001000 genes are preferentially expressed at a particular stage of the cell cycle $[3,4]$. The regulation of cell cycledependent gene expression can occur at one of several levels. As a result of complex networks of kinases and phosphatases, the activities of sequence specific transcription factors like E2F, B-Myb, and FOXM1 can be modulated [57]. Another level of cell cycle regulation is chromatin, which can occur both at the level of chromatin remodeling, histone modification, and modification-specific chromatin association (reviewed in [8]). A third level of regulation of cell cycle-dependent gene expression is the basal transcription machinery. Transcription initiation by the three RNA polymerases is regulated by distinct protein complexes including those containing the common subunit TBP (TATA binding protein) and complex-specific TAFs (TBP associated factors) (reviewed in [9-12]). These are in human cells: the SL1 complex (with TAF1A-C and JOSD3/TAFI41/MGC5306/TAF1D, hereafter referred to as TAFI41/TAF1D) for pol I transcription; TFIID (with TAF113) and B-TFIID (with BTAF1) for pol II transcription; and TFIIIB (with Brf1 and the loosely associated Bdp1 protein) for pol III transcription. Genetic and genome-wide functional analyses point to specific cell cycle functions of the TFIID TAFs. Studies in yeast have identified temperature sensitive mutations in several TAF genes which result in cell cycle arrest at either G1 or G2/M, and include the TAF1, TAF2, TAF5, and TAF10 genes [13-15]. Mammalian TFIID TAFs also have cell cycle roles. Murine F9 embryonal carcinoma cells lacking TAF10 arrest at G1 and undergo apopotosis [16]. A genetic screen for genes required for cell cycle progression in hamster cells identified TAF1 as cell cycle regulated gene 1 (CCG1) involved in G1 progression [17]. Genome-wide RNAi screens have identified TAF4 and TAF13 to be important for G1 progression [18]. This study also identified the preinitiation complex factors TFIIB and TFIIE $\beta$, which are recruited in response to TFIID promoter binding, to be important for G1 progression. In addition, the TFIIIB subunit Brf1 has been functionally linked to the cell cycle as its levels were found to be important for cell proliferation and oncogenic transformation, which seems mediated by tRNA ${ }^{\text {met }}$ levels [19].

Functional studies have mainly focused on the mechanisms underlying mitotic inhibition of transcription. These led to several models in which phosphorylation on TAFs regulate their activities. For SL1 mediated transcription, phosphorylation on TAF1C at T852 by cdk1/cyclin B has been implicated in mitotic inhibition [1]. Reactivation of transcription in G1 involved phosphorylation of the SL1 interactor UBF at S388 and S484 [20]. TFIID mediated transcription was marked by a mitotic hyperphosphorylation of TAF12, and phosphorylated TFIID showed decreased in vitro transcription activity [21]. This study also showed that several interactions within mitotic TFIID remained present. The TFIIIB subunit Brf1 is also subject to mitotic phosphorylation, which has been reported to lead to transcriptional repression and release of its interactor Bdp1 from chromatin [22,23].

Thus, phosphorylation on TAFs seems to be an important mechanism for mitotic inhibition of basal transcription factors. Far less information is available on the role of general transcription factors in regulating cell cycle specific patterns of gene expression. It is possible that changes in the phosphorylation status of individual TAFs regulate TBP complex function at cell cycle dependent genes. Another mechanism may be formation of TFIID subcomplexes with distinct functions, such as the Small TAF Complex consisting of TAF8, TAF9, and SPT7L [24,25]. However, it is unknown whether TBP subcomplexes have specific roles during the cell cycle.

The importance of TBP and TAFs for cell cycle progression prompted us to address the question whether protein complex formation around TBP is cell cycle regulated. We applied a quantitative mass spectrometry approach combined with affinity purification. This allowed us to determine changes in complex composition and relative abundances. In addition, novel phosphorylations present on TAFs in the TBP complexes SL1 and TFIID were identified and quantified by SILAC. Our results indicate that both the abundances in cell extracts and subunit phosphorylations are cell cycle regulated, while the compostions of TBP complexes remain unaffected. These findings present the first quantitative proteomic analysis of TBP complexes during the cell cycle, and offer new prospects on functional studies of transcriptional regulation during the cell cycle.

\section{Results and discussion Quantification of cell cycle-dependent TBP-containing protein complexes}

To investigate whether TBP-containing protein complexes are subjected to cell cycle-dependent alterations, we used a combination of double affinity purification and quantitative mass spectrometry. This procedure is outlined in Fig 1a. Stable HeLaS3 cells expressing flag-HA tagged TBP at near endogenous levels were used. These cells were generated by retroviral transduction using pBabe-puro-N-flagHA-TBP. After selection with puromycin, individual clones were picked, expanded and analyzed by immunoblot analysis using antibodies against flag, HA, and TBP (data not shown). This identified several clones with subendogenous expression of tagged TBP, one of which was used in this and our previous work [26]. The flag-HA 
A

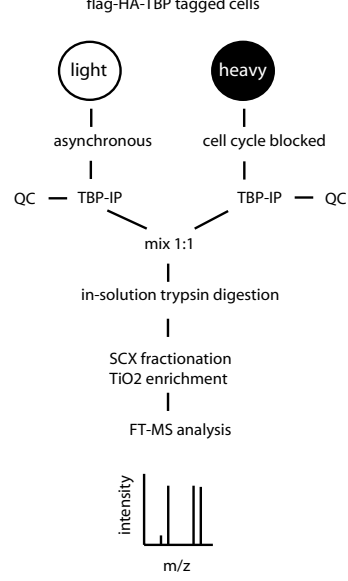

B

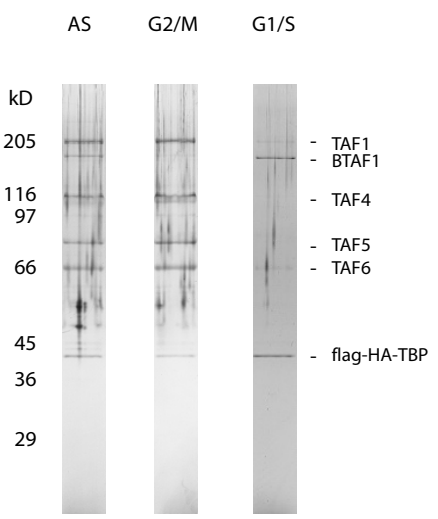

C

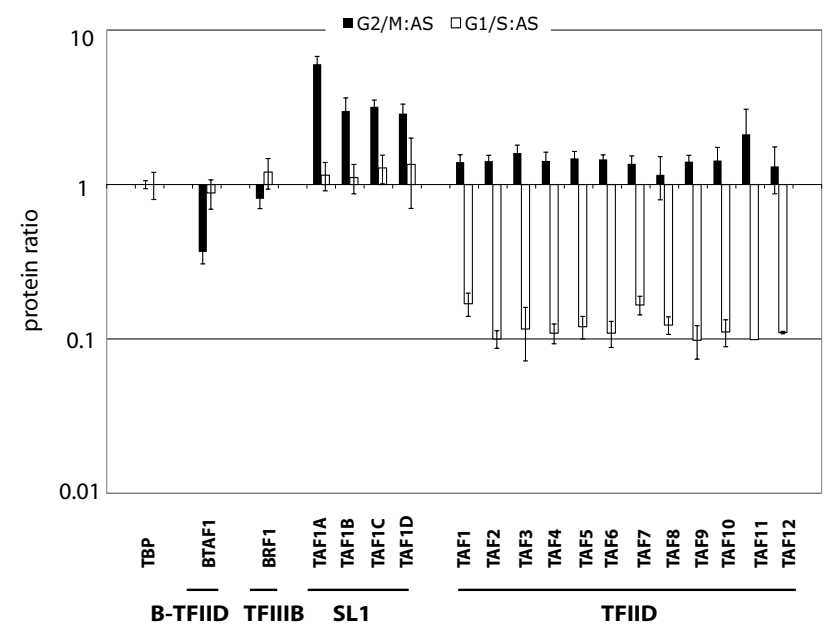

$\mathrm{D}$
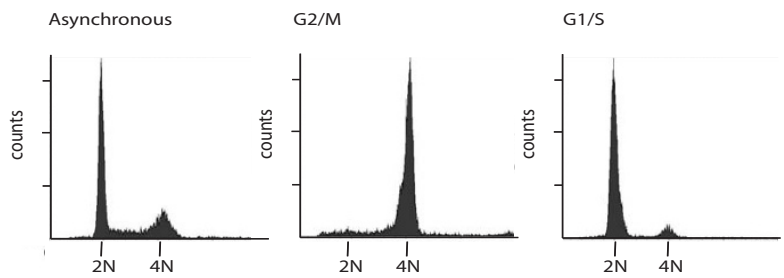

\section{Figure I}

Quantitation of TBP interactors in mitotic and S phase cells. (A) Experimental setup. TBP complexes were isolated from SILAC-labelled cells grown asynchronously or blocked at G2/M or GI/S. QC: $\sim 2 \%$ of the immunoprecipitates were analyzed on NuPage 4-I 2\% Bis-Tris gradient gel followed by silver staining for quality control, as shown in (B). The rest of the immunoprecipitates were digested in solution with trypsin. Tryptic fragments were fractionated by SCX and phosphopeptides were enriched using titanium dioxide. Peptides were identified and quantified by nano-LC-MS. (C) Quantitation of TBP interactors in G2/M blocked or GI/S blocked cells relative to asynchronous cells. Protein levels are normalized for TBP. Data represent means of at least three quantified peptides +/- SD. (D) FACS profiles of asynchronous (left panel), nocadozole-treated (middle panel), and double thymidine-treated (right panel) cells. 
epitope tags allowed double affinity purification of protein complexes using antibody-based resins and epitope peptide elutions. To obtain sufficient quantities, cells were grown in 15 liter-size bioreactors resulting in yields of 5$10 \times 10^{9}$ cells. We compared asynchronous (AS) cultures with G2/M-enriched (blocked using nocodazole) or G1/Senriched (blocked using double thymidine) cultures and used SILAC to allow quantitation by mass spectrometry $[27,28]$. SILAC was performed by metabolic labeling of cells either with 'light' versions of arginine and lysine $\left({ }^{12} \mathrm{C}_{6},{ }^{14} \mathrm{~N}_{4}\right.$-arginine and ${ }^{12} \mathrm{C}_{6},{ }^{14} \mathrm{~N}_{2}$-lysine) or with 'heavy' versions of these amino acids $\left({ }^{13} \mathrm{C}_{6},{ }^{15} \mathrm{~N}_{4}\right.$-arginine and ${ }^{13} \mathrm{C}_{6},{ }^{15} \mathrm{~N}_{2}$-lysine). FACS analysis of propidium iodidestained cells indicated that thymidine-treated cells were blocked at G1 just before S-phase, and showed an absence of cells with a DNA content indicative of cells in S-phase (Fig 1d). Nocadozole-treated cells were blocked at G2/M. Release experiments followed by FACS analysis confirmed cell cycle blocks as G2/M-blocked cells proceeded to G1, while G1/S-blocked cells proceeded to S-phase (data not shown). Whole cell extracts from the two conditions were separately purified, and subsequently mixed, concentrated, and analyzed by mass spectrometry. Because the samples were mixed after purification, and not before, potential exchange between the two samples during the affinity purification procedure was prevented. This was particularly important because we recently showed that BTAF1 is a highly dynamic complex subunit that dissociates and reassociates with TBP during immunopurification [26]. $2 \%$ of the immunoprecipitates were analyzed on silver stained gels for quality control (QC). This analysis revealed the TBP interactors: TAF1, BTAF1, TAF4, TAF5, TAF6, and tagged TBP itself (Fig 1b). These proteins seemed to change little at G2/M, while the TFIID-specific TAFs TAF1, TAF4, TAF5, and TAF6 seemed to be present at lower amounts relative to the B-TFID-specific BTAF1 and tagged TBP at G1/S (Fig 1c). The samples were analyzed by in-solution tryptic digestion followed by SCX fractionation, titanium oxide enrichment of phosphopeptides [29], and nano-LC-MS. This confirmed and extended the results obtained by analysis of silver stained gels.

On beforehand, the SILAC/titanium dioxide enrichment approach allows alterations in the detection of missing stable subunits, changes in relative abundances of TBP complexes, and cell cycle-dependent phosphorylations. Each of these events would be reflected by specific changes in the SILAC ratios after normalization relative to the abundance of TBP peptides. Missing stable subunits would be detected by strongly reduced SILAC ratios (relative to asynchronous). Our results indicate that all subunits of SL1 and TFIID remained complexed with TBP, both in G2/M- and in G1/S-arrested cells, as all subunits of these complexes clustered together (Fig 1c; see Additional File 1 for sequence coverage). No evidence was obtained for changes of specific TBP-subcomplexes. Changes in relative complex abundance were detected by changed SILAC ratios for all subunits of the TFIID complex. Fig 1c showed increased SILAC ratios for all TFIID subunits in G2/M (relative to non-synchronized), while SILAC ratios for these TAFs were reduced in G1/S cells. This suggested that the abundance of TFIID in these extracts was subject to cell cycle regulation. The abundance of B-TFIID was decreased in extracts derived from G2/M cells, but not in G1/S derived extracts. The abundance of SL1 was increased at G2/M, but not at G1/S, while the TFIIIB subunit BRF1 showed unchanged associations at G2/M and G1/S. We would like to point out that we have used a mild salt extraction protocol [30]) in order to maintain TBP complex integrity. Importantly, re-extraction of remaining chromatin pellets with higher salt solubilised a significant proportion of TBP complexes (data not shown). The total amount of cellular TAFs and TBP is not modulated during the cell cycle. This suggests that chromatin association of TBP complexes may be subject to cell cycle regulation. Therefore, we conclude that data on the abundances of TBP complexes in cellular extracts during the cell cycle should be interpreted with caution. Our SILAC approach indicates that TBP complexes remain intact at the G2/M and G1/S transitions, and that B-TFIID, SL1, TFIID but not TFIIIB display changes in abundance in cellular extracts derived from these transitions.

These results support previous observations by Segil et al. [21], who affinity purified TFIID from G2/M-enriched cells and found by co-immunoprecipitation that TBP, TAF1, TAF4, TAF5, TAF7, TAF9, TAF10, TAF12 remained present in mitotic TFIID. Also, mitotic SL1 and the stable components of TFIIIB (TBP and BRF1) have been reported to remain intact $[1,20,22,23]$. We extend these analyses with a quantitative analysis of G2/M-specific TBP interactions of the recently identified SL1 subunit TAFI41/TAF1D [10], and of the TFIID subunits not analyzed so far, including TAF2, TAF3, TAF6, TAF8, TAF11.

\section{Cell cycle-induced phosphorylations on TAFs}

A number of novel phosphorylations on TAFs in the context of their protein complexes were detected and quantified (Fig 2, Table 1, and Additional Files 2 and 3). This revealed highly G2/M-specific phosphorylations of the TFIID subunits TAF1 (T876) and TAF7 (S159), and of the SL1 subunit TAF1D (S234) (Table 1, Fig 2a,d,c). The T876 phosphorylation of TAF1 was interesting because of its proximity to G716, which is mutated to aspartic acid in ts 13 hamster cells resulting in a thermolabile form of TAF1 and to arrest of ts 13 cells in $\mathrm{G} 1$ at $39.5^{\circ} \mathrm{C}$ [17]. We made use of these cells to test involvement of T876 in G1 progression. Both the phosphopreventing T876A and the phosphomimicking T876D mutation were similarly active as wild type TAF1 in this assay, suggesting that this 
Table I: Quantification of phosphorylations on TBP interactors in cell cycle-blocked cells.

\begin{tabular}{|c|c|c|c|c|c|c|}
\hline Protein & Peptide & Position & $\begin{array}{l}\text { Phospopeptide } \\
\text { ratio (G2/M:AS) }\end{array}$ & $\begin{array}{l}\text { Protein ratio } \\
\text { (G2/M:AS) }\end{array}$ & $\begin{array}{l}\text { Phosphopeptidel } \\
\text { Protein ratio } \\
\text { (G2/M:AS) }\end{array}$ & Reference \\
\hline TAFI & TpGMDSNWWVLK & T876 & $|50.9|$ & 1.40 & 107.99 & this study \\
\hline TAF3 & RPLDSPPEAEELPAMK & $\mathrm{S} 183$ & 1.38 & 1.60 & 0.86 & this study; ref [3I] \\
\hline TAF4 & $\begin{array}{l}\text { SPPGVQPQLVLGGAA- } \\
\text { QTASLGTATAVQTGTPQR }\end{array}$ & S543 & 3.13 & 1.42 & 2.20 & this study \\
\hline TAF7 & YIESPPDVEKEVK & S159 & 15.77 & 1.36 & 11.58 & this study \\
\hline TAFI4I/TAFID & LAGDSpFIVSSEFPVR & S234 & $>200$ & 2.88 & $>200$ & this study \\
\hline
\end{tabular}

\begin{tabular}{|c|c|c|c|c|c|c|}
\hline Protein & Peptide & Position & $\begin{array}{l}\text { Phospopeptide } \\
\text { ratio (GI/S:AS) }\end{array}$ & $\begin{array}{l}\text { Protein ratio } \\
\text { (GI/S:AS) }\end{array}$ & $\begin{array}{l}\text { Phosphopeptidel } \\
\text { Protein ratio } \\
\text { (GI/S:AS) }\end{array}$ & Reference \\
\hline TAF3 & RPLDSpPEAEELPAMK & S183 & 0.11 & 0.12 & 0.94 & this study; ref [3I] \\
\hline TAF3 & QIQTPPPDAGK & T364 & 0.05 & 0.12 & 0.39 & this study \\
\hline TAF3 & RISPGPECTTPK & S427 & 0.02 & 0.12 & 0.19 & this study \\
\hline TAF6 & AAAPPQPSPPPPTK & S532 & 0.07 & 0.11 & 0.62 & this study \\
\hline TAF6 & QEAGDSPPPPAPGTPK & S653 & 0.12 & 0.11 & 1.13 & this study; ref [32] \\
\hline TAF7 & YIESPPDVEKEVK & SI59 & 0.11 & 0.17 & 0.63 & this study \\
\hline TAFI4I/TAFID & SRGSGFPFLESPENEK & SI37 & 1.43 & 1.35 & 1.06 & this study \\
\hline TAFI4I/TAFID & TQCIPYSPPKGEK & $\mathrm{S} 40$ & 1.94 & 1.35 & 1.44 & this study \\
\hline
\end{tabular}

Phosphorylations (indicated with a 'P' behind the modified residue) detected on TBP interactors were quantified in cell cycle-blocked cells relative to asynchronous cells and were corrected for protein levels. The sequence of the tryptic peptide detected is indicated.

residue is not essential for cell cycle progression (data not shown). We created ts 13 cell lines that stably express the phosphomutants of TAF1 at similar levels compared to endogenous hamster TAF1. These cells displayed unchanged expression levels of a selected set of genes including the cell cycle-independent genes for cyclophilin $\mathrm{B}$ and glucose phosphate dehydrogenase, and the G2/Mspecific genes for stk6 and cyclin B2 (data not shown). This suggested that phosphorylation of T876 is not critical for the cell cycle function of TAF1 or that it is redundant with other modifications. Slightly elevated (2.2-fold) phosphorylation of S543 TAF4 was detected in G2/M cells (Table 1). At G1/S, TAF3 was strongly dephosphorylated at S427, and to a lesser extend at S364 (Table 1, Fig 2e). Using a 2-fold cut off, other phosphorylations detected were cell cycle-independent. These included those on TAF3 (S183; Fig 2b), TAF6 (S532 and S653), and TAF1D (S40 and S137) (Table 1). All of these phosphorylations are novel, except S183 of TAF3, which appeared also cell cycle-independent in another study [31], and S653 of TAF6, which was not tested previously for cell cycle regulation [32].

A recent study using total proteome analysis also identified cell cycle-dependent phosphorylations of several TBP interactors including G1-specific phosphorylations on TAF7, and mitosis-specific phosphorylations on TAF7, TAF8, TAF9, and TAF1 [31]. Our analysis of TAFs in the context of their protein complexes can be distinguished from mapping of phosphosites in total cell lysates, which do not distinguish whether a certain TAF is present in complex with TBP or in another complex or as free protein. This is particularly relevant for TAF8 and TAF9, as they have been shown to be part of the Smal TAF and/or SAGA complexes $[24,25]$. We note that it is inherently difficult to determine the stoichiometry of a particular phos- 

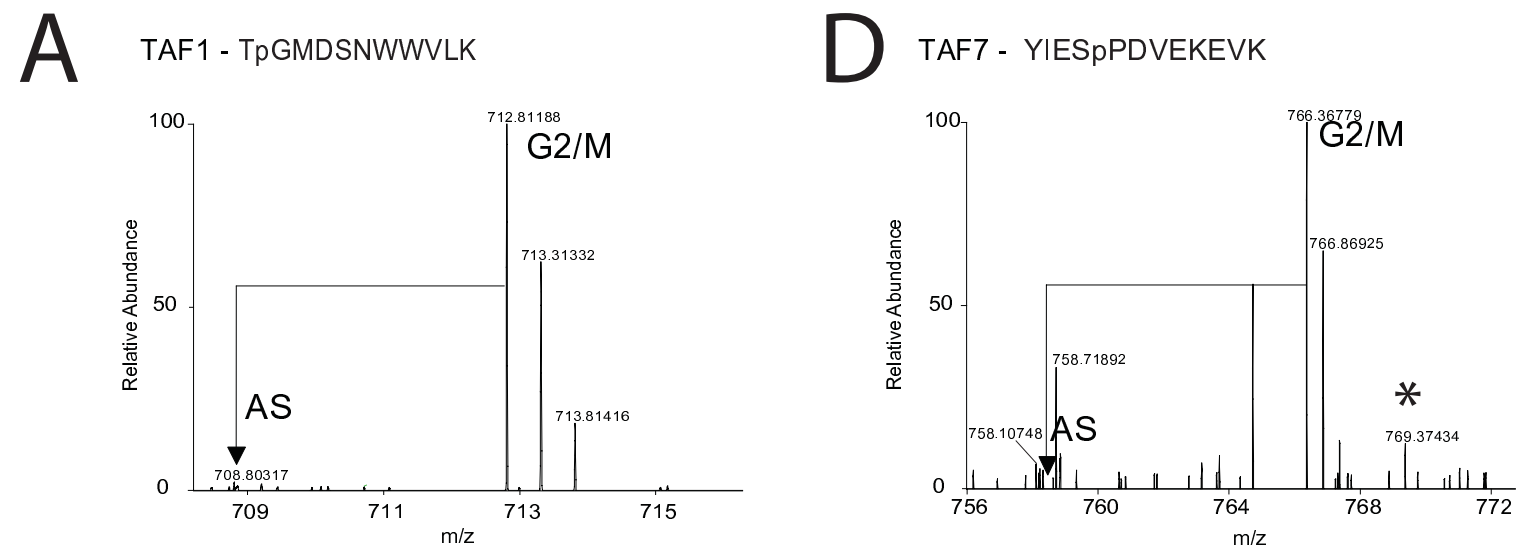

B

TAF3 - RPLDSPPEAEELPAMK
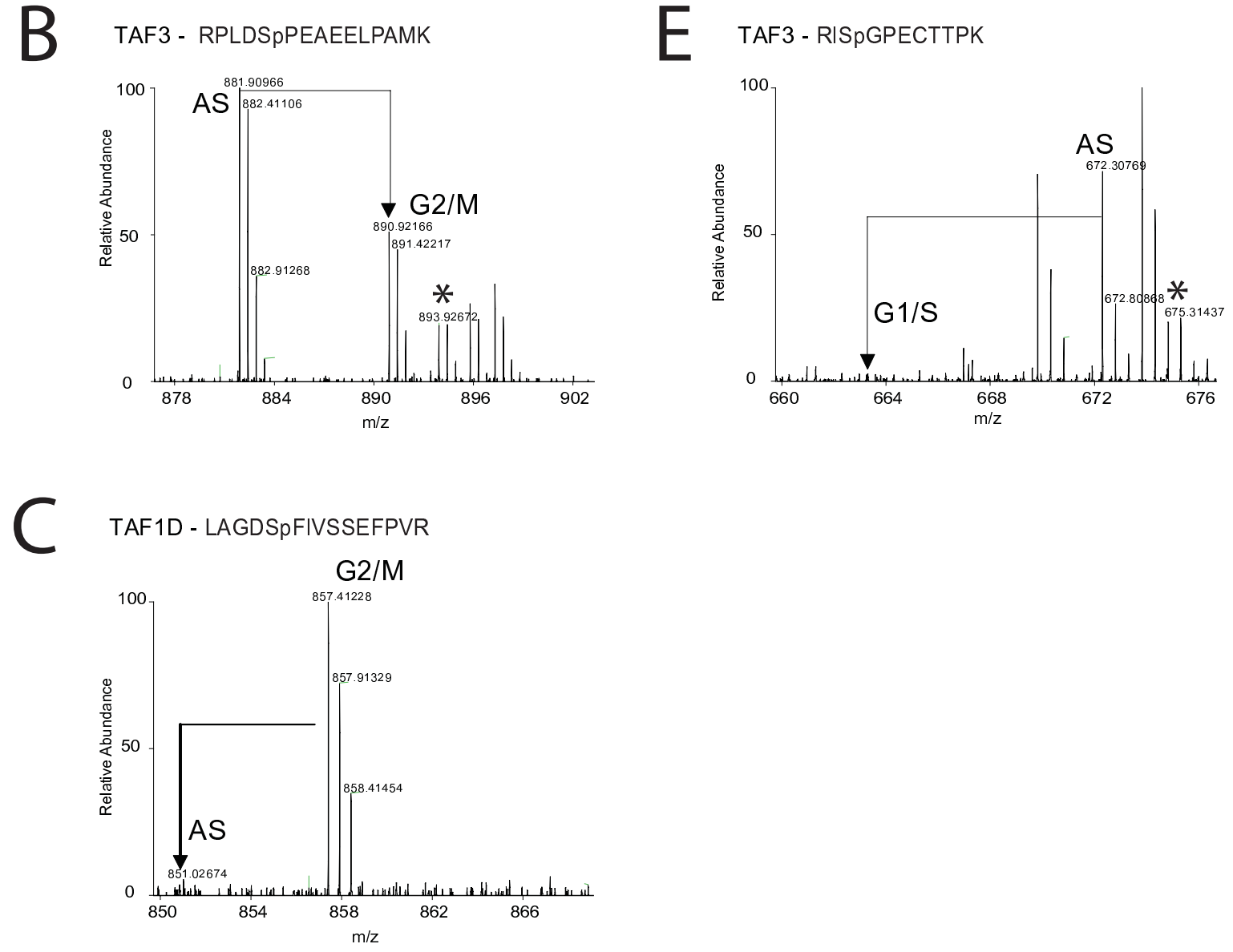

Figure 2

Cell cycle-dependent phosphorylations on TAFs. Quantitative mass spectra of highly cell cycle-regulated phosphorylations on TAFs. Peak pairs representing isotopic labeled phosphopeptides derived from asynchronous and cell cycle blocked cells are indicated. Peaks labeled $*$ are derived from isotopic labeled arginine-to-proline conversion, and should be added to the 'heavy' peaks for quantification. Shown are G2/M-induced phosphorylations on TAFI (A), TAFID (C), and TAF7 (D); GI/Sinduced dephosphorylation on TAF3 (E). (B) Cell cycle-independent phosphorylation on TAF3. All phosphorylations were quantified after correction for protein levels (see Table I). 
phorylation by mass spectrometry. This relates to potential differences in ionization properties of the phoshopeptide and its unmodified counterpart. For similar reasons it is not possible to exclude modification of a particular peptide.

Interestingly, the phosphorylation at S427 on TAF3, which is downregulated at G1/S, is located in a region in which many other phosphosites have been mapped [3335]. Out of all phosphosites detected in TAF3, all 17 (included the ones detected here) are located between S183 and T501 in the linker between the histone fold and PHD finger (Fig 3). Possibly the linker is involved in communication between the N-terminal histone fold, required for assembly into TFIID, and the C-terminal PHD finger, involved in recognition of histone $\mathrm{H} 3$ lysine 4 trimethyl-modified nucleosomes [36]. It is presently unknown whether any of these phosphorylations are also downregulated at G1/S, and whether this region is a true hotspot for phosphorylation or whether phosphorylations are just more easily detectable compared to other TAF3 regions.

The G2/M-specific phosphorylation at S159 of TAF7 is located in a TAF7-specific domain that spans residues 12178 (Fig 3). Part of this domain overlaps with its TAF1interaction domain, spanning residues 139-245. It is however unlikely that mitotic phosphorylation at S159 specifically affects the TAF7-TAF1 interaction, as both proteins have similar SILAC ratios in TBP purifications from G2/M cells (Fig 1c). TAF7 S159 lies just outside the domain that has been mapped to interact with transcriptional activators (spanning residues 38-118). This would be a way to inhibit the activity of TFID at mitosis and silence transcription. Whether this possibility is true should be determined in future experiments.

\section{Bioinformatic analysis of phosphosites}

Fig 3 shows the locations of the detected phosphorylations with respect to known protein domains. Most phosphorylations were present in linker regions between domains. To determine whether the phosphorylations were evolutionary conserved, an alignment of full length proteins from human, mouse, zebrafish, fruit flies, worm, and yeast was performed using clustal W [37] (Fig 4). TAFs present in TFIID were conserved in these organisms. However, the SL1-specific TAFI41/TAF1D was only conserved between human and mouse but not between human and lower eukaryotes. The alignments revealed that several residues found to be phosphorylated in human cells were conserved in mouse, zebrafish, and flies (TAF1 T876; TAF3 S183; TAF6 S653). Other residues were (semi) conserved (with either serine or threonine) from human to mouse and zebrafish (TAF3 S427; TAF6 S532, TAF7 S159), or from human to mouse and flies (TAF3 T364). Residues only conserved from human to mouse included
TAF4 S543, and TAF1D S40, S137, and S234. None of the phosphorylated residues were conserved in worm or yeast, however, in some cases the aligned residue was negatively charged mimicking phosphorylation. This was observed for residues aligned with TAF1 T876 in yeast (D533) and with TAF3 S427 in flies (D346). Interestingly, some phosphorylations were present in regions that were highly conserved from human to yeast (TAF1 T876; TAF6 S532; TAF7 S159) or from human to flies or worm (TAF3 S18 and S427; TAF6 S653), suggesting that they may be involved in regulating important functions of these proteins.

\section{Conclusions}

Recent advances in proteome technology allow a quantitative analysis of protein complexes and their post-translational modification status under various cellular conditions. Previous work suggested that TBP complexes play important roles in cell cycle progression, and that some of the TAFs remain associated with TBP and are subject to phosphorylation. Using SILAC and titanium dioxide enrichment of phosphopeptides, we here extend these analysis for all TAFs at the G2/M and G1/S transitions, and found that: 1)TBP complexes remain intact, 2) the abundances of TBP complexes in cellular cell extracts are cell cycle-dependent, and 3) numerous novel phosphorylation sites could be quantified. This indicated that subunits of TFIID and SL1 are subject to cell cycle-dependent phosphorylations. We speculate that phosphorylation of TAFs is involved in regulating the cell cycle dependent activity of TBP complexes.

\section{Methods \\ Cell culture}

Creation and culture of the HeLa S3 cell line stably expressing N-flag-HA-hTBP at near-endogenous levels has been described previously [26]. For SILAC analysis, cells were labelled using the heavy amino acids ${ }^{13} \mathrm{C}_{6},{ }^{15} \mathrm{~N}_{4^{-}}$ arginine and ${ }^{13} \mathrm{C}_{6},{ }^{15} \mathrm{~N}_{2}$-lysine or the light amino acids ${ }^{12} \mathrm{C}_{6},{ }^{14} \mathrm{~N}_{4}$-arginine and ${ }^{12} \mathrm{C}_{6},{ }^{14} \mathrm{~N}_{2}$-lysine as described [26]. Metabolic labeling was performed using heavy amino acids for G2/M cells compared to light amino acids for AS cells, and light amino acids for G1/S cells compared to heavy amino acids for AS cells. Scale-up of cell culture was performed using a $15 \mathrm{l}$ bioreactor (Applikon, NL). Cells were blocked in $\mathrm{G} 2 / \mathrm{M}$ using $60 \mathrm{ng} / \mathrm{ml}$ nocodazole for 17 hr. For cell cycle block at the G1/S transition, a double thymidine block was performed using $2.5 \mathrm{mM}$ thymidine and a sequence of $18 \mathrm{hr}$ for the first block, $8 \mathrm{hr}$ release, and $18 \mathrm{hr}$ for the second block. Cell cycle blocks were verified by FACS analysis of propidium iodide-stained cells.

\section{Preparation of protein extracts}

Protein extracts were prepared based on Dignam et al. [30]. All handling was performed at $4{ }^{\circ} \mathrm{C}$. Cells were washed two times in PBS, and were allowed to swell in 

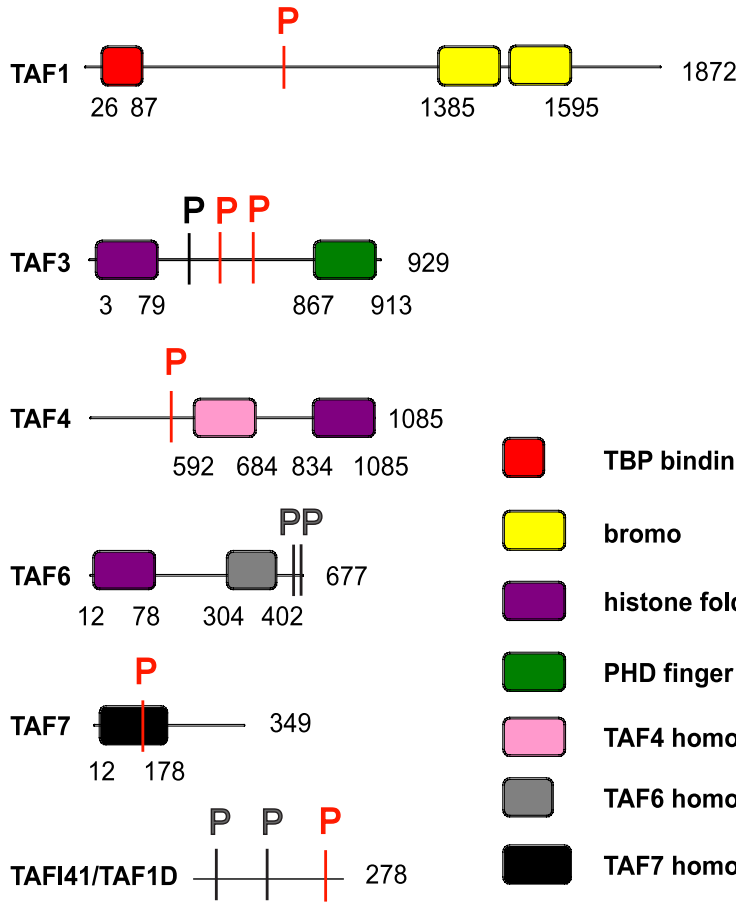

TBP binding

bromo

histone fold

PHD finger

TAF4 homology

TAF6 homology

TAF7 homology

\section{Figure 3}

Location of phosphorylations on TAFs with respect to protein domain organization. Phosphosites are indicated with $\mathrm{P}$ using the following colour code: black, unchanged; red, cell cycle regulated (relative to asynchronous), using a 2-fold cut-off.

three packed cell volumes (PCVs) of buffer A (10 mM Tris$\mathrm{HCl} \mathrm{pH} 7.9,20 \%$ glycerol, $1.5 \mathrm{mM} \mathrm{MgCl}_{2}, 0.1 \mathrm{mM}$ EDTA, $10 \mathrm{mM} \mathrm{KCl}, 1 \mathrm{mM}$ DTT, $1 \%$ protease inhibitor cocktail (Sigma P8340), 1\% phosphatase inhibitor cocktail 1 (Sigma P2850), 1\% phosphatase inhibitor cocktail 2 (Sigma P5726). After centrifugation at $1500 \mathrm{rpm}$ for 10 min, the cell pellet was resuspended in $3 \mathrm{PCV}$ of buffer A. Cells were lysed by douncing using a tight pestle, and then centrifuged at $3000 \mathrm{rpm}$ for $15 \mathrm{~min}$. The supernatant was brought to $100 \mathrm{mM} \mathrm{NaCl}$ and represents the cytoplasmic extract (CE). The pellet was resuspended in $5 \mathrm{ml}$ per $10^{9}$ cells of buffer B (20 mM HEPES-NaOH pH 7.9, 25\% glycerol, $1.5 \mathrm{mM} \mathrm{MgCl}_{2}, 0.2 \mathrm{mM}$ EDTA, $0.42 \mathrm{M} \mathrm{NaCl}, 1 \mathrm{mM}$ DTT, protease and phosphatase inhibitors as above), and incubated for $30 \mathrm{~min}$ with rotation. This mixture was centrifuged at 15,000 rpm for $20 \mathrm{~min}$. The supernatant represents the nuclear extract (NE).

\section{Affinity purification of TBP complexes}

Extracts were dialyzed overnight in buffer C $(20 \mathrm{mM}$ HEPES-NaOH pH 7.9, 20\% glycerol, 0.2 mM EDTA, 100 $\mathrm{mM} \mathrm{NaCl}, 1 \mathrm{mM}$ DTT, protease and phosphatase inhibitors as above). Extracts were centrifuged at $100,000 \times \mathrm{g}$ for
$45 \mathrm{~min}$ to remove precipitated material. Extracts representing whole cell extract $(\mathrm{CE}+\mathrm{NE})$ were double affinity purified as described [26]. Extracts from asynchronous cells and cell cycle blocked cells were compared by SILAC and quantitative mass spectrometry. TBP complexes were purified separately to prevent exchange of subunits during the purification procedure as described [26]. Purified complexes were mixed at a 1:1 ratio based on the total protein content of the input material and denatured immediately by methanol/chloroform precipitation. Precipitated proteins were stored at $-80^{\circ} \mathrm{C}$ until analysis by mass spectrometry.

\section{In-solution digestion of purified protein complexes}

Purified protein complexes were dissolved in a solution of $8 \mathrm{M}$ urea in $50 \mathrm{mM}$ ammonium bicarbonate $\mathrm{pH} 8$, and incubated with $5 \mu \mathrm{g}$ of endoproteinase LysC (Roche Diagnostics) for $4 \mathrm{hr}$ at $37^{\circ} \mathrm{C}$. Following reduction and alkylation using $2 \mathrm{mM}$ DTT and $4 \mathrm{mM}$ iodoacetamide, respectively, the sample was diluted to $2 \mathrm{M}$ urea with 50 $\mathrm{mM}$ ammonium bicarbonate $\mathrm{pH} 8$, and incubated overnight with $5 \mu \mathrm{g}$ trypsin at $37^{\circ} \mathrm{C}$.

\section{SCX Chromatography and online TiO2 based two- dimensional chromatography}

After digestion, the protein digests were desalted using a small plug of C18 material (3 M Empore C18 extraction disk) packed into a GELoader Tip similar to as previously described [38] onto which $10 \mu \mathrm{L}$ of Aqua C18 (5 $\mu \mathrm{m}, 200$ A) material was placed. The eluate was dried completely. The G2/M sample was reconstituted in $20 \%$ (v/v) acetonitrile, $0.05 \%(\mathrm{v} / \mathrm{v})$ formic acid and analyzed using strong cation exchange chromatography and subsequent fractions were analyzed on a $\mathrm{TiO} 2$ based 2D-nanoflowHPLC as described [29]. The G1/S sample was reconstituted in 5\% formic acid, and immediately analyzed on the TiO2 based 2D-nanoflow-HPLC system, without prior SCX fractionation as described by Pinkse et al. [29]

\section{Mass Spectrometry}

The 2D-LC system was online coupled to a LTQ Orbitrap mass spectrometer (Thermo Electron, Bremen, Germany), which operated in data-dependent mode, automatically switching between MS, MS/MS, and neutral loss-driven $\mathrm{MS}^{3}$ acquisition. Full-scan MS spectra (from $\mathrm{m} / \mathrm{z} 300$ to $1500)$ were acquired in the Orbitrap with a resolution of 60,000 at $\mathrm{m} / \mathrm{z} 400$ after accumulation to a target value of 500,000 . The three most intense ions at a threshold above 5000 were selected for collision-induced fragmentation in the linear ion trap at a normalized collision energy of 35\% after accumulation to a target value of 10,000 . The datadependent neutral loss settings were chosen to trigger an $\mathrm{MS}^{3}$ event after a neutral loss of $49 \pm 0.5 \mathrm{~m} / \mathrm{z}$ units was detected in the most intense fragment ion. 


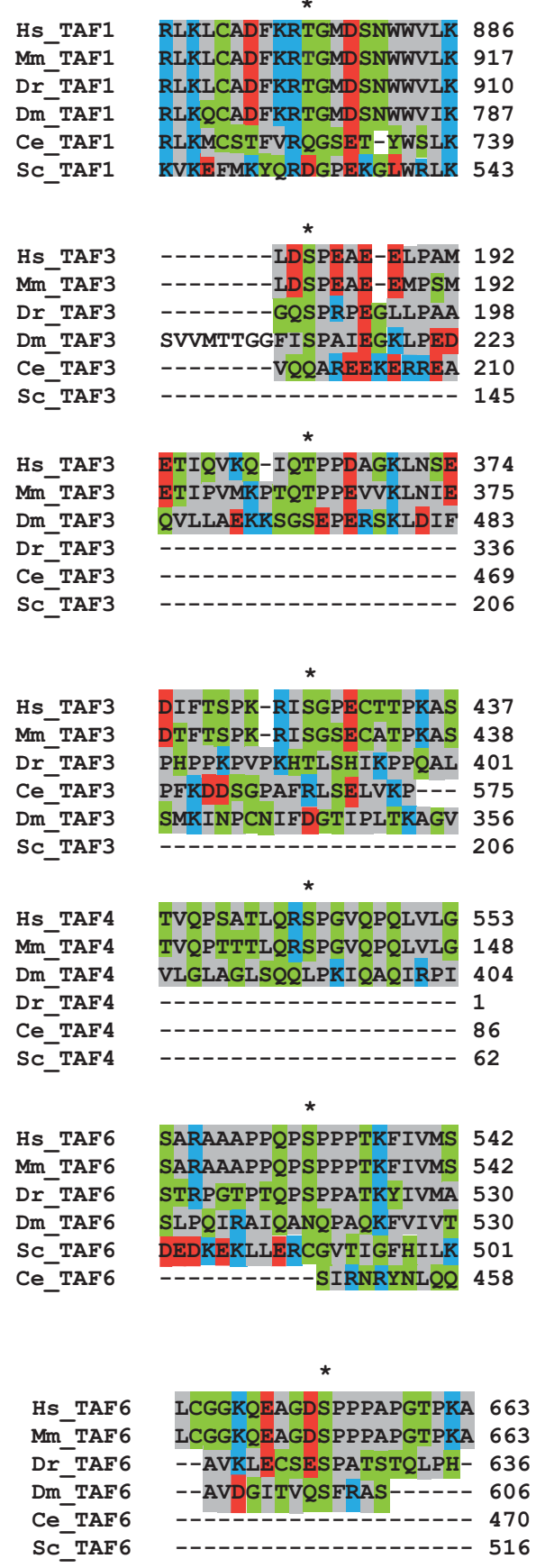

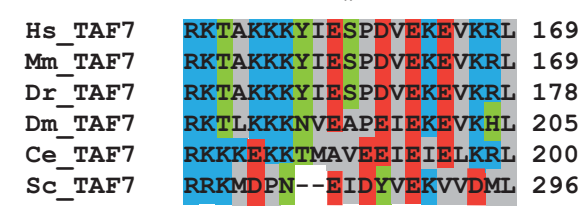

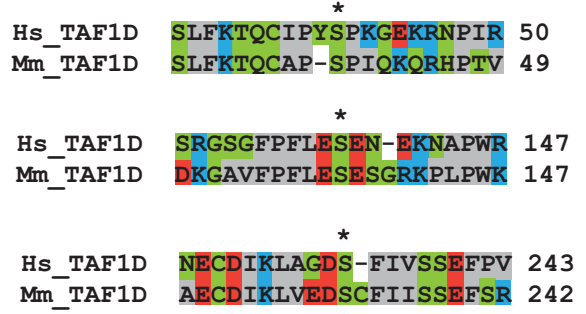




\section{Protein Identification}

In a post analysis process, all MS2 and MS3 spectra were converted to single DTA files using Bioworks software, Version 3.1. An in-house Perl-script was used to assign the original and accurate parent mass to all MS3 spectra, enabling accurate parent mass identification. For protein identification, MS/MS data were submitted to the International Protein Index (IPI) human (release 3.36; 69012 entries) using Mascot Version 2.2 (Matrix Science) with the following settings: 20 ppm and $0.8 \mathrm{Da}$ deviation for precursor and fragment masses, respectively. Trypsin was specified as the proteolytic enzyme, and up to two missed cleavages were allowed. Carbamidomethyl cysteine was set as fixed modification; $\mathrm{N}$-terminal acetylation, oxidized methionines, ${ }^{13} \mathrm{C}_{6}{ }^{-15} \mathrm{~N}_{2}$ lysine, ${ }^{13} \mathrm{C}_{6}{ }^{-15} \mathrm{~N}_{4}$ arginine and phosphorylation of serine and threonine residues were set as variable modifications. The following was done to verify identified phosphosites: 1) Mascot scores of potential phosphosites at alternative residues in the identified peptides were determined and were found to be lower compared to the phosphosites presented in all cases, 2) All MS/MS spectra were manually verified.

\section{Protein quantification}

Relative quantification ratios of identified proteins were derived by MSQuant, which is open source software [39]. Briefly, peptide ratios between the monoisotopic peaks of "normal" and "heavy" forms of the peptide were calculated and averaged over consecutive MS cycles for the duration of their respective LC-MS peaks in the total ion chromatogram using FT-survey. Peptide ratios of the same protein were averaged to give protein abundance ratios as well as the respective standard deviation. Peptide ratios obtained by using the MSQuant software were all inspected manually. Our experiments, in agreement with data from other groups, showed that HeLa cells convert ${ }^{13} \mathrm{C}_{6}{ }^{-15} \mathrm{~N}_{4}$-arginine to ${ }^{13} \mathrm{C}_{5}{ }^{15} \mathrm{~N}_{1}$-proline. In these experiments the conversion was estimated as $13.5 \%$. We corrected the peptide ratio for this conversion as described previously [26]. After the proline conversion correction, protein ratios were normalized on the TBP level.

\section{Bioinformatic analysis}

Sequence aligments were made using clustal W software [37] using full cDNA sequences of TAFs and their homologs. The stretch containing the phosphorylated residue +/- 10 amino acids was manually edited. Omission of an alignment indicates that no homologous region or protein was identified.

\section{Competing interests}

The authors declare that they have no competing interests.

\section{Authors' contributions}

WWMP, AK, AJRH, and HTMT contributed to experimental design, data interpretation, and manuscript preparation. Mass spectrum analysis was performed by AK. Tissue culture, biochemical experiments, and bioinformatic analysis were performed by WWMP and MPAB. WWMP and AK contributed equally. AJRH and HTMT contributed equally. All authors read and approved the final manuscript.

\section{Additional material}

\author{
Additional file 1 \\ Sequence coverage for identified TBP interactors. \\ Click here for file \\ [http://www.biomedcentral.com/content/supplementary/1477- \\ 5956-7-46-S1.XLS]

\section{Additional file 2} \\ MS/MS spectra and Mascot scores for identified phosphopeptides in \\ the G2/M:AS sample. \\ Click here for file \\ [http://www.biomedcentral.com/content/supplementary/1477- \\ 5956-7-46-S2.PDF]

\section{Additional file 3} \\ MS/MS spectra and Mascot scores for identified phosphopeptides in \\ the G1/S:AS sample. \\ Click here for file \\ [http://www.biomedcentral.com/content/supplementary/1477- \\ 5956-7-46-S3.PDF]
}

\section{Acknowledgements}

We thank Nikolay Outchkourov for critically reading the manuscript. We also thank Rene Medema, Livio Kleij, and Geert Kops for suggestions on cell cycle analysis, and members of the Timmers and Heck laboratories for discussions and suggestions. This work was supported in part by grants from the Netherlands Proteomics Centre and the European Union (HPRNT2002-0026I and LSHG-CT-2006-037445).

\section{References}

I. Heix J, Vente A, Voit R, Budde A, Michaelidis TM, Grummt I: Mitotic silencing of human rRNA synthesis: inactivation of the promoter selectivity factor SLI by cdc2/cyclin B-mediated phosphorylation. EMBO J 1998, 17:7373-7381.

2. Leresche A, Wolf V], Gottesfeld JM: Repression of RNA polymerase II and III transcription during $M$ phase of the cell cycle. Exp Cell Res 1996, 229:282-288.

3. Bar-Joseph Z, Siegfried Z, Brandeis M, Brors B, Lu Y, Eils R, Dynlacht $B D$, Simon I: Genome-wide transcriptional analysis of the human cell cycle identifies genes differentially regulated in normal and cancer cells. Proc Natl Acad Sci USA 2008, 105:955-960.

4. Whitfield ML, Sherlock G, Saldanha AJ, Murray JI, Ball CA, Alexander KE, Matese JC, Perou CM, Hurt MM, Brown PO, Botstein D: Identification of genes periodically expressed in the human cell cycle and their expression in tumors. Mol Biol Cell 2002, I3:1977-2000. 
5. Blais A, Dynlacht BD: E2F-associated chromatin modifiers and cell cycle control. Curr Opin Cell Biol 2007, 19:658-662.

6. Laoukili J, Kooistra MR, Bras A, Kauw J, Kerkhoven RM, Morrison A, Clevers $\mathrm{H}$, Medema $\mathrm{RH}$ : FoxMI is required for execution of the mitotic programme and chromosome stability. Nat Cell Biol 2005, 7:126-136.

7. Neganova I, Lako M: GI to $\mathbf{S}$ phase cell cycle transition in somatic and embryonic stem cells. J Anat 2008, 213:30-44.

8. Egli D, Birkhoff G, Eggan K: Mediators of reprogramming: transcription factors and transitions through mitosis. Nat Rev Mol Cell Biol 2008, 9:505-516.

9. Cler E, Papai G, Schultz P, Davidson I: Recent advances in understanding the structure and function of general transcription factor TFIID. Cell Mol Life Sci 2009, 66:2123-2134.

10. Gorski J], Pathak S, Panov K, Kasciukovic T, Panova T, Russell J, Zomerdijk JC: A novel TBP-associated factor of SLI functions in RNA polymerase I transcription. EMBO J 2007. 26: I560-I568.

II. Tora $L$ : A unified nomenclature for TATA box binding protein (TBP)-associated factors (TAFs) involved in RNA polymerase II transcription. Genes Dev 2002, 16:673-675.

12. Willis IM: A universal nomenclature for subunits of the RNA polymerase III transcription initiation factor TFIIIB. Genes Dev 2002, 16:1337-1338.

13. Apone LM, Virbasius CM, Reese JC, Green MR: Yeast TAF(II)90 is required for cell-cycle progression through G2/M but not for general transcription activation. Genes Dev 1996, 10:2368-2380.

14. Kirschner DB, vom Baur E, Thibault C, Sanders SL, Gangloff YG, Davidson I, Weil PA, Tora L: Distinct mutations in yeast TAF(II)25 differentially affect the composition of TFIID and SAGA complexes as well as global gene expression patterns. Mol Cell Biol 2002, 22:3178-3193.

15. Walker SS, Shen WC, Reese JC, Apone LM, Green MR: Yeast TAF(II) I 45 required for transcription of GI/S cyclin genes and regulated by the cellular growth state. Cell 1997, 90:607-6I4

16. Metzger D, Scheer E, Soldatov A, Tora L: Mammalian TAF(II)30 is required for cell cycle progression and specific cellular differentiation programmes. EMBO J 1999, 18:4823-4834.

17. Sekiguchi T, Yoshida MC, Sekiguchi M, Nishimoto T: Isolation of a human $X$ chromosome-linked gene essential for progression from GI to $\mathbf{S}$ phase of the cell cycle. Exp Cell Res 1987, 169:395-407.

18. Kittler R, Pelletier L, Heninger AK, Slabicki M, Theis M, Miroslaw L, Poser I, Lawo S, Grabner H, Kozak K, et al: Genome-scale RNAi profiling of cell division in human tissue culture cells. Nat Cell Biol 2007, 9:140I-I4I2.

19. Marshall L, Kenneth NS, White RJ: Elevated tRNA(iMet) synthesis can drive cell proliferation and oncogenic transformation. Cell 2008, I 33:78-89.

20. Voit R, Grummt I: Phosphorylation of UBF at serine 388 is required for interaction with RNA polymerase $I$ and activation of rDNA transcription. Proc Natl Acad Sci USA 200I, 98:1363|-13636.

21. Segil N, Guermah M, Hoffmann A, Roeder RG, Heintz N: Mitotic regulation of TFIID: inhibition of activator-dependent transcription and changes in subcellular localization. Genes Dev 1996, 10:2389-2400.

22. Fairley JA, Scott PH, White RJ: TFIIIB is phosphorylated, disrupted and selectively released from tRNA promoters during mitosis in vivo. EMBO I 2003, 22:584 I-5850.

23. Gottesfeld JM, Wolf VJ, Dang T, Forbes DJ, Hartl P: Mitotic repression of RNA polymerase III transcription in vitro mediated by phosphorylation of a TFIIIB component. Science 1994, 263:8I-84

24. Demeny MA, Soutoglou E, Nagy Z, Scheer E, Janoshazi A, Richardot $M$, Argentini M, Kessler P, Tora L: Identification of a small TAF complex and its role in the assembly of TAF-containing complexes. PLoS ONE 2007, 2:e316.

25. Muller $\mathrm{F}$, Tora $\mathrm{L}$ : The multicoloured world of promoter recognition complexes. EMBO J 2004, 23:2-8.

26. Mousson F, Kolkman A, Pijnappel WW, Timmers HT, Heck AJ: Quantitative proteomics reveals regulation of dynamic components within TATA-binding protein (TBP) transcription complexes. Mol Cell Proteomics 2008, 7:845-852.
27. Gingras AC, Gstaiger M, Raught B, Aebersold R: Analysis of protein complexes using mass spectrometry. Nature Reviews Molecular Cell Biology 2007, 8:645-654.

28. Ong SE, Blagoev B, Kratchmarova I, Kristensen DB, Steen H, Pandey A, Mann M: Stable isotope labeling by amino acids in cell culture, SILAC, as a simple and accurate approach to expression proteomics. Molecular \& Cellular Proteomics 2002, I:376-386.

29. Pinkse MWH, Mohammed S, Gouw LW, van Breukelen B, Vos HR, Heck AJR: Highly robust, automated, and sensitive on line TiO2-based phosphoproteomics applied to study endogenous phosphorylation in Drosophila melanogaster. Journal of Proteome Research 2008, 7:687-697.

30. Dignam JD, Lebovitz RM, Roeder RG: Accurate transcription initiation by RNA polymerase II in a soluble extract from isolated mammalian nuclei. Nucleic Acids Res 1983, II: | 475- 1489.

31. Dephoure N, Zhou C, Villen J, Beausoleil SA, Bakalarski CE, Elledge S), Gygi SP: A quantitative atlas of mitotic phosphorylation. Proceedings of the National Academy of Sciences of the United States of America 2008, 105:10762-10767.

32. Gnad F, Ren SB, Cox J, Olsen JV, Macek B, Oroshi M, Mann M PHOSIDA (phosphorylation site database): management, structural and evolutionary investigation, and prediction of phosphosites. Genome Biology 2007, 8(I I):R250.

33. Phosida phosphorylation data base [http://www.phosida.de]

34. Beausoleil SA, Jedrychowski M, Schwartz D, Elias JE, Villen J, Li J, Cohn MA, Cantley LC, Gygi SP: Large-scale characterization of HeLa cell nuclear phosphoproteins. Proc Natl Acad Sci USA 2004, 101:12130-12135.

35. Olsen JV, Blagoev B, Gnad F, Macek B, Kumar C, Mortensen P, Mann $M$ : Global, in vivo, and site-specific phosphorylation dynamics in signaling networks. Cell 2006, I 27:635-648.

36. Vermeulen M, Mulder KW, Denissov S, Pijnappel WW, van Schaik FM, Varier RA, Baltissen MP, Stunnenberg HG, Mann M, Timmers HT: Selective anchoring of TFIID to nucleosomes by trimethylation of histone $\mathrm{H} 3$ lysine 4. Cell 2007, I 3 I:58-69.

37. Thompson JD, Higgins DG, Gibson TJ: Clustal-W - Improving the Sensitivity of Progressive Multiple Sequence Alignment through Sequence Weighting, Position-Specific Gap Penalties and Weight Matrix Choice. Nucleic Acids Research 1994 , 22:4673-4680.

38. Rappsilber J, Ishihama Y, Mann M: Stop and go extraction tips for matrix-assisted laser desorption/ionization, nanoelectrospray, and LC/MS sample pretreatment in proteomics. Analytical Chemistry 2003, 75:663-670.

39. MSQuant [http://msquant.sourceforge.net/]

40. UniProt [http://www.uniprot.org/]

\begin{tabular}{|} 
Publish with Biomed Central and every \\
scientist can read your work free of charge \\
"BioMed Central will be the most significant development for \\
disseminating the results of biomedical research in our lifetime. " \\
Sir Paul Nurse, Cancer Research UK \\
Your research papers will be: \\
• available free of charge to the entire biomedical community \\
• peer reviewed and published immediately upon acceptance \\
• cited in PubMed and archived on PubMed Central \\
• yours - you keep the copyright \\
Submit your manuscript here: \\
http://www.biomedcentral.com/info/publishing_adv.asp
\end{tabular}

